\title{
Gentrificação no Brasil e no contexto latino como expressão do colonialismo urbano: 0 direito à cidade como proposta decolonizadora
}

\author{
Gentrification in Brazil and the latin context as an expression of urban \\ colonialism: the right to the city as a decolonizing proposal
}

Cristhian Magnus De Marco[a] (D), Paulo Junior Trindade dos Santos[a] (D), Gabriela Samrsla Möller[a] (D)

[a] Universidade do Oeste de Santa Catarina (UNOESC), Chapecó, SC, Brasil

Como citar: De Marco, C. M., Santos, P. J. T., \& Möller, G. S. (2020). Gentrificação no Brasil e no contexto latino como expressão do colonialismo urbano: o direito à cidade como proposta decolonizadora. urbe. Revista Brasileira de Gestão Urbana, 12, e20190253. https://doi.org/10.1590/2175-3369.012.e20190253

\section{Resumo}

O fenômeno gentrificador no Brasil e no contexto latino sofre os efeitos da colonialidade do poder, pois associado a práticas positivas e naturais da organização da cidade, como a reurbanização, a revitalização e a reutilização, cujo efeito é velar as consequências reais da gentrificação, quais sejam a polarização social, a criminalização da pobreza e a hostilização da cidade, o que se deve à presença do colonialismo (combatido pela des/colonialidade, porém perpetrado ainda pela colonialidade do poder). Nesse contexto social, uma abordagem de/colonialista (e não mais des/colonialista) pode ser proposta pelo direito à cidade, capaz de repolitizar o fenômeno gentrificador e desvelar suas consequências nocivas, acentuadas em um contexto de globalização, extirpando assim os traços da colonialidade do poder e possibilitando dialogar sobre os diversos impactos do fenômeno gentrificador na vida das pessoas, principalmente das mais pobres.

Palavras-chave: Gentrificação. América Latina. Colonialidade do poder. Decolonização. Direito à cidade.

\begin{abstract}
The gentrifying phenomenon in Brazil and the Latin context suffers the effects of the coloniality of power because associated with positive and natural practices of city organization, such as re-urbanization, revitalization, and reuse, whose effect is to veil the real consequences of gentrification, which be the social polarization, criminalization of poverty and the hostility of the city, which is due to the presence of colonialism (fought by decoloniality, but still perpetrated by the coloniality of power). In this social context, de/colonialist (and no longer decolonial) approach can be proposed by the right to the city, capable of re-politicizing the gentrifying phenomenon and unveiling its harmful consequences, accentuated in a context of globalization, thus removing the traces of coloniality. of power and enabling dialogue about the various impacts of the gentrifying phenomenon on people's lives, especially the poorest
\end{abstract}

Keywords: Gentrification. Latin America. Coloniality of power. Decolonization. Right to the city.

CMM é professor, doutor em Direito, e-mail: cristhian.demarco@unoesc.edu.br

PJTS é professor, doutor em Direito, e-mail: pjtrindades@hotmail.com

GSM é mestranda em Direito, e-mail: gabi.moller@hotmail.com 


\section{Introdução}

[...] el lujo de omitir la violencia de la gentrificación de nuestro ámbito es un lujo político que nace de los privilegios de raza y clase (Smith, 2012, p. 76).

A urbanização acelerada das cidades contrasta com a desigualdade, pobreza e exclusão, as quais não têm sido reduzidas, inclusive só aumentam (Neri, 2019; OXFAM Brasil, 2018): a renda da classe média teve queda de $4,16 \%$ entre 2014 e 2019 , sendo que a renda do $1 \%$ mais rico subiu $9,5 \%$ e a do $50 \%$ mais pobre diminuiu $18 \%$. Sem um crescimento equilibrado, essas disparidades afetam as relações sociais em vários níveis da vida das pessoas, dentre um deles ressalta-se o nível da habitação, pertencimento e moradia, diretamente relacionado à existência humana, à construção da subjetividade, à qualidade de vida e à inclusão social.

Essa contraposição, já afirmada por Lefebvre (2011, p. 137), é fundamental para relacionar que o avanço da urbanização (crescimento, revitalização, urbanização, regeneração, turistificação e gentrificação num aspecto positivo), observado em várias cidades brasileiras e latinas, não se relaciona com a redução de desigualdades, sendo indispensável compreender como dois fenômenos contrapostos coexistem nas cidades. Segundo a hipótese deste estudo, essa convivência somente é possível através do fenômeno gentrificador, que possibilita que as desigualdades existam, se aprofundem e também sejam legitimadas no contexto urbano, observado, nesse diapasão, através de sua expressão de colonialidade do poder, conforme deve ser compreendido na América Latina, pois, para que ocorra a urbanização atual, é necessário manejar processos de reestruturação e higienização do território voltados a atender as necessidades do mercado, reconfigurando territórios.

A luta contra mecanismos de estruturação do poder é capaz de efetuar uma reconfiguração do campo semântico do urbanismo, o que se propõe seja feito pela matriz da decolonialidade, que identifica no discurso a existência da colonialidade do poder. Como até então ficou claro, a abordagem da gentrificação no presente trabalho será considerando-a como nociva à sociedade e principalmente aos mais pobres, aqueles que tradicionalmente fogem à construção eurocêntrica e colonial do homem. Nessa medida, é possível tornar visível o fenômeno gentrificador, identificando o contexto que dá forma ao fenômeno, para assim apartá-lo das correntes hegemônicas que consideram a gentrificação como um reflexo natural da sociedade competitiva. Busca-se politizar o termo através do direito à cidade, permitindo a visibilidade das facetas do fenômeno gentrificador, reflexo de um desenvolvimento urbano desigual.

\section{O fenômeno da gentrificação: primeiros aportes}

A gentrificação ${ }^{1}$ inicialmente foi identificada como fenômeno de mudança socioespacial, caracterizada pela chegada de setores de classe média (gentrys ${ }^{2}$, os gentrificadores) ou atividades comerciais, acompanhada da saída da população de renda mais baixa, através de processos marcados pela higienização social, com o fim de atender as necessidades do mercado acarretando uma série de impactos sociais, como a diferenciação do espaço das cidades (Mendes, 2015, p. 210). Alcunhado nos anos 60, foi associado a um fenômeno restrito ao centro da cidade e à especulação de seu preço, por concentrar área de alto interesse, a gentrificação ocorre em locais não mais limitados ao centro. Para compreender o processo gentrificador, uma das abordagens possíveis do fenômeno consiste na inserção de conceitos decorrentes de estudos coloniais, como o racismo urbanístico, que associa a gentrificação a dimensões

\footnotetext{
${ }^{1}$ Sobre a história do conceito de gentrificação, marcado por seu caráter crítico frente aos fenômenos de exclusão e criado para denunciar políticas de afrouxamento do controle do Estado sobre o mercado e a mercantilização urbana, ver: Lees et al. (2008, p. 45-51), Wyly (2019, p. 15-18), Smith (2012, p. 87-88), Janoschka et al. (2014, p. 13), Constela (2013, p. 223).

2 Ruth Glass, socióloga inglesa que cria o termo "gentrificação" no ano de 1964, buscou, de forma irônica, designar pelo termo o fenômeno da substituição de uma população residencial existente por uma gentry, que para os ingleses significa "pessoas de boas condições e boa posição social" (Lees et al., 2008, p. 45). A socióloga já percebia a existência de um fenômeno de colonização, utilizando a abordagem descolonizadora como crítica à lei de planejamento urbano de Londres, responsável por afrouxar o controle do Estado sobre aluguéis, aumentando assim a especulação do mercado (Wyly, 2019, p. 15-16).
} 
como etnicidade e raça, reconhecendo que a conquista dos espaços ocorre quase sempre em zonas da cidade, nas quais residem pessoas de certa nacionalidade, origem étnica, gênero e cor, observando na gentrificação um movimento de colonialidade do poder que não oferece resistência às pessoas afetadas (Cordero, 2016, p. 101-102).

Como projeto econômico, a transformação dos espaços nas cidades ocasiona melhorias estruturais, pois há um aumento no recolhimento de impostos, aumento dos financiadores e atuação dos agentes imobiliários, de negócios e limpeza do espaço, escondendo, por seus impactos positivos, um projeto político e ideológico do Estado e das elites, que facilita a limpeza social, levando os menos desejáveis longe do espaço urbano (Shin, 2018, p. 151). Os favoráveis ao processo de gentrificação recorrem a uma terminologia como "reciclagem do bairro", "melhoramento", "renascimento", "modernização" e outros, como formas de moderar as conotações raciais e classicistas da gentrificação (Smith, 2012, p, 76; Graham, 2011): ocorre que o sucesso da renovação é limitado a beneficiar uma classe, a alta (Betancur, 2014, p. 6). Essa forma de abordar a gentrificação associa-se a correntes denominadas "neoclássicas" do conceito, que continuam a dominar teorias e políticas urbanas, devido à apropriação das políticas urbanas pelo mercado (Lees et al., 2008, p. 48-51).

A readequação espacial ocasionada pela gentrificação, cuja consequência é a remoção de pessoas, remaneja pessoas, tornando-as nômades, por práticas apoiadas e perpetradas pelo próprio Estado - a elite ${ }^{3}$ depende do poder do Estado de repressão para manter a distância os pobres (Davis, 2008, p. 104-108). É nítido que para um estrato da sociedade, aqueles que participam e desfrutam da dinâmica urbana, a gentrificação se apresenta como revitalização do ambiente, porém, para outros, aqueles excluídos do desfrute da cidade, sofrem o impacto do imenso custo social (Atkinson, 2004, p. 111).

0 fenômeno gentrificador, no que aqui interessa compreender, desde sua construção/revelação, toma diferentes formas de expressão, de modo que hoje não é mais restrito a um fenômeno observado nos centros das cidades, mas sim como todo o processo de mobilidade ascendente que usa o espaço urbano para escalar outras pessoas, para subir em uma hierarquia social; é a falsa naturalização da desigualdade social - explorando e abusando das espacialidades e ideias do urbanismo, destruindo formas de existência em nome da acumulação (Wyly, 2019, p. 15-16), como é o caso da gentrificação simbólica ${ }^{4}$. Não se restringe às questões de residência 5 , mas inclui debates como o impedimento do uso do espaço público pelos cidadãos mediante sua privatização e controle de atividades, o que expande a discussão sobre a transformação de locais públicos, transformados, privatizados e erradicados de política (Janoschka et al., 2014, p. 27).

Os atuais estudos ${ }^{6}$ desvelam várias dimensões do fenômeno gentrificador: demográfico, econômico, político, cultural, imaginário e simbólico (Cordero, 2016, p. 104), o que denota sua associação como forma de colonialismo urbano, pois, na medida em que encontra força privilegiando os brancos, uma classe, uma expressão de gênero e suas identidades, a partir de uma cisão de classe e com a predominância de uma estética e cultura marcadamente colonial, apropria-se do espaço urbano e de sua história (Atkinson \& Bridge, 2005, p. 2).

\section{Nuances da gentrificação no contexto brasileiro e latino}

Mesmo que a conceituação do termo gentrificação não decorra do estudo da geografia e do urbanismo latino, é aplicável também nele, levando-se em consideração, porém, quando do estudo da gentrificação a partir da visão dos países europeus e da América do Norte, algumas particularidades que somente

\footnotetext{
${ }^{3}$ Em observação brilhante, Marcuse (2015, p. 1266) aponta que os gentrificadores que consomem os empreendimentos muitas vezes também são vítimas de forças econômicas poderosas, evitando assim que se generalize e crie um "ódio entre classes" que de nada adianta para a resolução do problema urbano. A compreensão é o primeiro passo.

${ }^{4}$ Ver próxima seção.

${ }^{5}$ Outras expressões do fenômeno são a gentrificação rural, a condominialização, as supergentrificações, a estudantificação. Todos esses termos possuem a semelhança de dividir algo em comum: uma mudança socioeconômica e cultural devido à colonização/recolonização da classe média (Lees et al., 2008, p. 129-132).

${ }_{6}^{6}$ De acordo com Maloutas (2012, p. 48), o termo gentrificação deve ser desafiado constantemente, revelando/lembrando seus pressupostos contextuais implícitos e comparando-os com as realidades contextuais da análise a cada momento.
} 
ocorrem no contexto latino, devido às culturas locais e ao aprofundamento da desigualdade ${ }^{7}$. Mesmo que a gentrificação seja fenômeno que se observa nas cidades em tempos e escalas diferentes, a partir dos anos 1990 os países latino-americanos constroem as bases que darão permeabilidade à gentrificação, abrindo suas portas à viabilidade de assumir juros baixos para o setor imobiliário e o potencial de reutilização de propriedades existentes, acarretando os fenômenos acima delineados, potencializados pela precariedade regional da América Latina.

Expressa-se, aqui, pelas seguintes formas, a título de exemplo: renovação de centros históricos (patrocinada pelo Banco Mundial e Programa Interamericano de Desenvolvimento e pela Unesco) voltados ao turismo através de concessões para o âmbito privado; emergência de mercados imobiliários como não vista em nenhum local ao norte (Janoschka et al., 2014, p. 25); gentrificação ocorre em periferias; supergentrificação; diferença no conceito de subúrbio para os países europeus/norteamericanos (Leão \& Brito, 2018, p. 70) ${ }^{8}$. Existem particularidades do fenômeno gentrificador latinoamericano em contraste com regiões desenvolvidas que não podem ser ignoradas pelo pesquisador.

Devido aos maiores níveis de desigualdade, concentração de pobreza e informalidade no uso da propriedade, o papel do Estado é fundamental para compreender as inversões imobiliárias em espaços até então não atrativos ao capital. Em países latino-americanos torna-se fundamental que o Estado atue como mediador para que o capital privado interfira, dando-se, aqui, muito destaque à gentrificação simbólica, pois, a gentrificação não se dá somente com a chegada de uma classe média com potencial de compra, mas sim através de programas públicos que atraem investimentos privados e consumidores (Cócola Gant et al., 2016, p. 13).

No Rio de Janeiro, onde $40 \%$ da população vive em favelas, a chegada do capital imobiliário somente é possível com uma prévia militarização do espaço e programas de regulação de propriedade, assim como através da realização de eventos esportivos. Assim, mais do que uma forma que emerge das dinâmicas locais, a gentrificação foi introduzida e expandida pelos governos nacionais ${ }^{9}$ na busca da criação de novos mercados e o avanço urbano competitivo. Em que pese a América Latina ser uma região vasta e diferenciada, a colonização e a neocolonização inseriram em seus Estados uma única forma de fazer política (Betancur, 2014, p. 2-3).

0 deslocamento ${ }^{10}$ social reflexo da política gentrificadora torna-se mais violento e de maior escala aqui, uma vez que existe relação entre o nível de pobreza de um espaço e o nível de violência que o Estado e o capital utilizam para converter o espaço em nova oportunidade de benefícios, tornando a América Latina cada vez mais propensa à existência de políticas revanchistas (Cócola Gant et al., 2016, p. 14). Exemplo seriam os grandes eventos que o Brasil vivenciou nos últimos dez anos, cujo reflexo foi um semnúmero de supergentrificação ${ }^{11}$.

O fenômeno aprofunda a criminalização da pobreza: é comum os governos do mundo todo justificarem a remoção de favelas e pessoas de modo a combater o crime (Davis, 2008, p. 114-120), para pacificar os assentos informais (Janoschka et al., 2014, p. 20) e para realizar supergentrificação. Em todos os casos a justificação vem acompanhada de ampla aceitação social pelos extratos mais altos - e por, inclusive, aqueles não tão altos, porém que assumem uma posição favorável à higienização urbana e sem que haja medidas dignas aos habitantes locais, tais como: informação à população, despejo com prévio reassentamento, contraditório social, inexistência de coação, aviso prévio (Bello \& Queiroz, 2017, p. 1.925), medidas mínimas para garantir a participação democrática.

\footnotetext{
${ }^{7}$ O que revelam, por exemplo, os estudos de Zapata et al. (2018), López-Morales et al. (2016), Janoschka (2016), Cócola Gant et al. (2016) e Betancur (2014). Indica-se a leitura para melhor conhecer as particularidades do fenômeno gentrificador na América Latina.

${ }^{8}$ Sobre experiências latinas de gentrificação, ver Betancur (2014, p. 7-9).

${ }^{9}$ Sobre o processo de higienização social perpetrado no Brasil, ver Davis (2008, p. 114 e ss).

${ }^{10}$ As novas construções teóricas sobre gentrificação, nos termos do que defende Elliott-Cooper et al. (2020, p. 4) devem focar nas consequências para os grupos que sofrem o efeito desse fenômeno, principalmente o deslocamento das famílias causadas, o "lado escuro da gentrificação". Os deslocamentos induzidos pela gentrificação seriam uma forma de desamparo distinta das outras formas de mobilidade involuntária, não somente a substituição direta dos mais pobres pelos mais ricos.

${ }^{11}$ Sobre o ponto, ver Rolnik (2019, p. 221-253).
} 
Globalização e colonialidade do poder: gentrificação como geografia própria de um projeto global e reflexo no contexto latino-americano

Segundo Quijano (2007, p. 123), com a globalização vivemos o primeiro sistema-mundo global, criando uma forma global de fazer política, consolidando as cidades em um formato global (Betancur, 2014, p. 3), afastando a ideia sociológica clássica de sociedade como sistema delimitado (Hall, 2006, p. 67-71). Atrás do mercado, como objetivo último de um projeto econômico, existe a missão cristã e secularizadora do colonialismo moderno, pois o moderno não existe sem o colonial - seu lado sombrio, ao lado das luzes (Mignolo, 2003, p. 47 e 379, 2017, p. 9).

Bauman (2009, p. 11) sintetiza que as cidades se transformaram em depósitos de problemas causados pela globalização, estando todos diante de uma tarefa que não podem nem sonhar em resolver: a tarefa de encontrar soluções locais para contradições globais; a gentrificação, nessa perspectiva, assume uma nova dinâmica global, estando onipresente nas cidades.

0 poder das relações do capitalismo e colonialismo mudou no século passado, mas formas incipientes de colonialismo aparecem hoje em uma economia globalizada (Quinteros, 2015, p. 324), como a colonialidade do poder, aprofundada por um sistema global e em rede, mediante as seguintes dimensões: governamental, por meio da privatização de serviços públicos, aliança entre público e privado; econômica, incentivos fiscais, protagonismo da cidade como ente econômico e competitivo e especulação imobiliária; territorial, pela promoção de volta a áreas centrais e adoção de tributos de áreas centrais para espaços periféricos; social, pela abertura de fissura entre as classes sociais (Cordero, 2016, p. 9293), concedendo à parte mais forte um poder de veto e controle da vida e do sustento do mais débil (Sousa Santos, 2010, p. 141). As cidades hoje expressam-se não como condição de território, mas por uma dimensão empreendedora (Holm, 2010, p. 89-90).

o capital não reconhece o local, particularidade, move-se sem fronteiras físicas, políticas ou ideológicas. Disso decorre que não somente os gentrys de classe média e alta são brancos, mas sua expressão cultural-paisagística, seus aspectos estéticos são predominantemente brancos, refletindo assim sua cultura e história no espaço urbano.

Para obnubilar os impactos sociais da gentrificação, o Estado constrói projetos de habitação social em locais afastados da cidade, periferias distantes, tidas como verdadeiras armadilhas da pobreza ao lado da cidade e do luxo tecnológico (Rolnik, 2019, p. 255 e ss.). 0 deslocamento das "periferias da periferia" constitui técnica comprovada de pacificação e controle de grupos marginalizados e oprimidos localizados por suas características de colonizados: cor, etnia, sexo, renda, cultura - conectada pelo sonho da propriedade privada. Essa estratégia segrega, aumentando também a violência, a insurgência política, racial e ideológica.

Colonialidade do poder: manifestações de uma sociedade segregadora, excludente e revanchista

Maldonado-Torres $(2007$, p. 31) explica que "colonialidade" difere-se de "colonialismo". O segundo denota relação política e econômica, a soberania de um povo sobre outro povo/nação. A colonialidade, por sua vez, refere-se a um padrão de poder, à forma pela qual o trabalho, o conhecimento, a autoridade e as relações intersubjetivas se articulam entre si, sendo resultado da construção moderna da subjetividade. 0 colonialismo, assim entendido, precederia à colonialidade, mas a colonialidade sobrevive ao (fim do) colonialismo.

O colonialismo, para além de ser uma política de Estado (como sucedia no período de pré-independência), é, sobretudo, uma gramática social muito mais ampla, atravessando o espaço público, privado, a sociabilidade, instaurando um verdadeiro modo de viver que implica criar cisões e hierarquias sociais (Sousa Santos, 2010, p. 15). A independência (formal) de vários países, nesse sentido, não liberta os países, pois ainda existe a colonialidade do poder (da fala, da hierarquia social, cultural, a submissão, a produção do conhecimento) (Mignolo, 2003, p. 129).

A razão eurocêntrica dominante (colonialidade do poder) cria formas de existência, e as defende como universais: o rigor do saber, maculando o diferente como irracional/ignorante/inculto; tempo linear, como se a história tivesse sentido e direção única e conhecida, através do progresso, revolução, modernização, desenvolvimento, crescimento; globalização, por meio do qual valores são postos pelos países centrais do sistema mundial; e classificação social, distribuição das populações por categorias que 
naturalizam as hierarquias como raça e gênero, sendo fundamentais para a relação capital/trabalho (Quijano, 2007, p. 117).

Na América Latina, a colonialidade do poder acentua-se em especial grau por não constituir o grupo "desenvolvido", decorrente dos estigmas sociais da população local e do espaço subalterno dentro da história mundial.

Por meio dessa construção, a inferioridade é natural e insuperável, o inferior é inferior porque é, simplesmente. A não existência é local e particular: o capitalismo econômico é um objetivo racional e inquestionável (Sousa Santos, 2010, p. 23-24).

Decorrente desse contexto é compreender que a gentrificação nunca pode ser rejeitada como uma lente irrelevante para entender as zonas periurbanas ou ex-urbanas de cidades pós-coloniais, pois é sobretudo um processo geopolítico reflexo de tensões do urbanismo transnacional.

0 processo e o conceito de gentrificação em sua forma neoclássica e positiva sempre estiveram envolvidos com a linguagem colonial - inovação, criatividade, progresso - voltada a impulsos imobiliários e políticos - revitalização, regeneração, sustentabilidade (Wyly, 2019, p. 13-14) para os quais o reflexo social é a desumanização e a invisibilidade (Maldonado-Torres, 2007, p. 145-151), efeito de uma rejeição das consequências da colonialidade do poder junto às cidades.

Os aspectos simbólicos que decorrem da colonialidade do poder delimitam socialmente o lugar das pessoas, ficando parte em um campo do invisível. É a posição subjetiva, base socialmente configurada, que permite existir processos gentrificadores. Uma linha divisória racial, de gênero, de classe determina uma estigmatização discursiva da narrativa simbólica da sociedade, traduzindo-se em um espaço urbano homogêneo que corresponde aos gostos de uma parte da sociedade que domina a hierarquia social, característica dos sujeitos que definem a espacialidade contemporânea.

Ao considerar a gentrificação como a nova fronteira urbana, Smith (2012, p. 46-53) cria uma metáfora a partir do imaginário do espírito aventureiro dos pioneiros urbanos (homens brancos), "civilizando" os lugares. Esse imaginário carrega um grande peso ideológico, pois a gentrificação contagia comunidades de classes trabalhadoras, retirando os pobres e adaptando bairros inteiros, de modo que a fronteira ideológica racionaliza a diferenciação social e torna a exclusão como algo natural e inevitável.

Nesse sentido, a classe pobre é definida facilmente como incivil, sendo a essência do imaginário da fronteira domar a cidade selvagem, justificando uma incivilidade no coração da cidade. A construção desse mito da fronteira racionaliza e justifica a violência institucional.

Amendola (2000, p. 312) aponta que da concepção de "explorados e exploradores" passa-se à noção de "incluídos e excluídos" na cidade, uma sociedade marcada pela distância entre os que estão dentro e os que estão fora da fronteira. Os excluídos podem constituir, inclusive, um perigo para a própria existência dos incluídos

A nova rede global, unida ao desmantelamento do Estado social ou à união Estado e âmbito privado, tem como consequência o aumento do valor do solo/propriedade. A vida segura, hoje, é buscada por outros meios, em um mundo individualizado e privatizado. Assim, a defesa do lugar assume contornos do bairro, a comunidade local ganha força: os outros lugares passam a não importar, mas aquele lugar, $o$ seu lugar, importa. As pessoas procuram o equivalente a um abrigo nuclear pessoal, e a comunidade passa a significar isolamento, muros e portões vigiados. A comunidade é a mesmice, ausência do outro, o outro que teima ser diferente (Bauman, 2003, p. 100-105).

Nessa perspectiva de rede global, os aspectos do colonialismo se manifestam na universalização de formas de administração, de modo que a gentrificação é compreendida amplamente como forma de política pública voltada à regeneração urbana, focando na classe média como os novos salvadores da cidade (Atkinson \& Bridge, 2005, p. 2). Não há espaço para falar o contrário, o conteúdo crítico do termo gentrificação, cunhado pela sociologia, perde espaço num contexto como o vivenciado.

A polícia urbana torna-se "revanchista" contra os excluídos socialmente (Graham, 2011), buscando assim solucionar o problema da higienização social, pois as classes perigosas de nossos tempos são as incapacitadas para reintegração e classificadas como não assimiláveis. A cidade tende a desaparecer para deixar espaço a bairros dotados não somente de funcionalidades, mas de riqueza simbólica, onde não existe possibilidade de 
conversação horizontal entre os habitantes. A possibilidade de definir a identidade social por uma conotação territorial é consequência da experiência urbana, até o ponto de representar o objetivo de uma vida inteira, pois manifesta um poder aquisitivo, o status e o estilo de vida em geral. A morada expressa uma complexa intersecção tanto entre capital cultural - gosto, competências -, social - relações pessoais, grupos de pertencimento -, como econômico - poder aquisitivo e patrimônio (Amendola, 2000, p. 121-125).

Para afirmar as políticas espaciais da cidade revanchista, a constante conexão causal entre crime e imigração, superpopulação e pobreza, são combinações de uma pseudociência formada para a justificar a exclusão social (Smith, 2012, p. 295-296). A criminalização da pobreza é reflexo de um mundo onde a estratificação social reflete um modelo de exclusão e degradação, na medida em que apontam os pobres como pertencentes a uma "subclasse", associando-a a sua inclinação criminosa. A insegurança moderna não se conecta com a perda de segurança, mas com sua assimilação em um mundo que foi construído e organizado voltado à segurança e controle. Ou seja, compreende-se que com capacidades e ferramentas certas, é possível obter uma segurança completa. Como isso nunca é alcançado, essa falha, porém, é explicada colocando-se culpa em alguém, o que implica apontar delinquentes (Bauman, 2009, p. 109).

A narrativa de criminalização da pobreza já é acompanhada por políticas de precarização que estigmatizam os territórios, inclusive, através de intervenções que promovem a segurança urbana - pacificação e militarização. Por isso que na América Latina a reestruturação urbana é muitas vezes legitimada e chancelada pelo poder público, visando eliminar e substituir para abrir caminho à especulação (Mendes, 2015, p. 210). Mecanismos simbólicos perseguem a ordem e regulação das condutas que habitam os bairros gentrificados, valendo-se da presença da polícia para pacificar os bairros, assim como da presença de vídeo-câmera e vigilância. Desse modo, são impostos os estilos de vida da classe média baseada no consumo, fomentando boas práticas vizinhas (Cordero, 2016, p. 104).

\section{Direito à cidade como decolonização: aportes para uma nova abordagem da gentrificação para o Brasil e para a América Latina}

Quinteros (2015, p. 323) realiza uma pergunta fundamental para o início da reflexão sobre o direito à cidade em uma perspectiva global e latino-americana: "The question for the colonized mind in this time of globalization is not simply 'What rights do we have?' but instead a much more sinister one: 'who has rights?"'12. Há muito o direito à cidade é mascarado, limitando-se ao direito de acesso a serviços, qualidade de vida, equipamentos, porém, compreendido assim, somente aqueles com maior capital teriam acesso ao direito à cidade.

É necessário associar o direito à cidade ao sentido de politização social contra mazelas urbanas (identificação de focos de gentrificação), o que permite dar um escopo jurídico/político às lutas sociais, transformando assim as subjetividades (dado que o poder colonial se concentra no discurso da colonialidade) e permitindo lutas anti-gentrificadoras.

A luta contra a perversidade dos mecanismos de mercado começa com uma nova abordagem do fenômeno gentrificador, levando em consideração o cenário atual, desvelando o significado de conceitos como revitalização, reurbanização e um conjunto de discursos sociais, econômicos e simbólicos que precisam ser repensados ${ }^{13}$ (Janoschka et al., 2014, p. 21). Nessa perspectiva, o direito à cidade deve ser examinado por um enfoque global de decolonialidade (Quinteros, 2015, p. 323).

As várias lutas sociais, como as dos campesinos, feministas, indígenas, por direitos humanos, contra racismo e contra a homofobia, voltam-se a transpor a linha do mundo sub-humano para o mundo humano, pois o "[...] pensamento moderno ocidental continua a operar mediante linhas abissais que dividem o mundo humano do sub-humano, de tal forma que princípios de humanidade não são postos

\footnotetext{
${ }^{12}$ A questão para a mente colonizada neste tempo de globalização não é simplesmente “Quais direitos temos?”, mas uma questão muito mais sinistra: "quem tem direitos?" (tradução nossa).

${ }^{13}$ Ressalta-se que os mecanismos simbólicos são uma dimensão altamente interessante do estudo sobre gentrificação e direito à cidade por serem um passo adiante da construção feita por Lefebvre em sua obra que inaugura mundialmente os debates sobre direito à cidade.
} 
em causa por práticas desumanas" (Sousa Santos, 2007, p. 10). As lutas sociais, desse modo, são fundamentais como resistência e produção de vida, demarcando contornos que o pensamento muitas vezes ignora. 0 direito à cidade, desde já ressalte-se, deve ser pensado como essa prática de resistência.

0 "pensamento abissal" demonstra que a epistemologia moderna diferencia o visível do invisível. O invisível compreende a zona colonial, o que demarca a divisão do humano para o sub-humano. Transforma a ciência na única epistemologia, deixando outras formas de conhecimento totalmente invisíveis por não se adaptarem à forma do conhecimento visível. A linha abissal dá forma à injustiça social global, pois ela é, sobretudo, injustiça cognitiva global (Sousa Santos, 2010, p. 31-37).

O giro colonial, a abordagem de/colonizadora (sem o "s"), visa complementar a categoria de des/colonização (com o "s") utilizada pelas ciências sociais ao final do século XX. Ambas as abordagens têm por objetivo desvelar as práticas violentas e preconceituosas perpetradas com relação a determinada cultura e povos. A abordagem decolonizadora é construída posteriormente à abordagem descolonizadora.

Hoje, vive-se em um mundo descolonizado e pós-colonial, decorrente da formação dos Estados-nação em países periféricos, porém ainda marcado pela transição do colonialismo moderno para uma colonialidade global, um processo diferente do que ocorreu na modernidade, mas cujo principal efeito é ainda manter os países de "terceiro mundo" (termo usado para o controle das subjetividades), como a América Latina, em uma posição periférica e subordinada, mas não pela dominação territorial, e sim epistemológica. A atual organização do mundo nos conduz a uma ressignificação, em um formato pós-moderno, das exclusões causadas pelas hierarquias epistêmica, espiritual, racial/étnica e de gênero/sexualidade implantadas pela modernidade.

A implicação fundamental da colonialidade do poder e do movimento decolonizador compreende que o mundo não foi completamente descolonizado. 0 giro decolonial se faz necessário porque a ciência social não encontrou ainda a forma de incorporar os conhecimentos subalternos ao processo de produção de conhecimento, razão pela qual busca a criação de novas epistemologias. A cumplicidade das ciências sociais com a colonialidade do poder exige a emergência de novos lugares institucionais e não institucionais onde os subalternos possam falar e ser escutados (Castro-Gómez \& Grosfoguel, 2007, p. 13-21).

As primeiras descolonializações foram incompletas, já que se limitaram à independência jurídico-política das periferias. A segunda descolonização, chamada de decolonialidade, dirige-se à hierarquia das múltiplas relações (raciais, étnicas, sexuais, epistêmicas, econômicas e de gênero) que a primeira descolonização deixou intacta. Assim, o mundo, no século XXI, exige uma decolonialidade que complementa a descolonização (Castro-Gómez \& Grosfoguel, 2007, p. 10-19).

Para a proposta de um direito à cidade decolonizador, o conceito de sociologia das emergências de Sousa Santos (2010, p. 25-28) expressa muito bem as bases para se pensar no direito à cidade: substituir o vazio do futuro segundo o tempo linear por outro de pluralidades e possibilidades. Assim, a sociologia das emergências consiste em soluções alternativas que existem no horizonte das possibilidades concretas, quebrando a ideia de que o futuro está determinado. Abre-se um horizonte de possibilidades, investigando-se as alternativas.

Para Mignolo (2007, p. 27-33), a decolonialidade é a energia e o grito sufocado dos humilhados, esquecidos, marginalizados, que não se deixam manejar pela lógica da colonialidade e não acreditam nos contos de fada de sua retórica. 0 pensamento decolonial busca o fim do paradigma moderno, na busca do: "[...] reconocimiento de todo humano como miembro real de una misma especie, más allá de todo escepticismo misantrópico" (Maldonado-Torres, 2007, p. 159-161). Nesse sentido, o enfoque decolonial ressignifica as exclusões epistêmicas, espirituais, raciais, étnicas, de gênero, ocorridas na modernidade (Castro-Gómez \& Grosfoguel, 2007, p. 13-21).

0 direito à cidade deve ser parte do movimento decolonial, pois expressa uma forma de insurgência social, manifestando os contornos de uma cidade, e rebelde, como forma de luta urbana (Opillard, 2018, p. 117). 0 urbano funciona como espaço de ação e revolta política (Harvey, 2014, p. 212-213), pois, segundo Rolnik (1995, p. 8), imbricada com a natureza da cidade está a organização da vida social e a necessidade de gestão da produção coletiva; indissociável à existência material da cidade está sua existência política. É na cidade o local onde ocorrem e eclodem os conflitos sociais (Corrêa, 1989, p. 7), de modo que a luta pelo direito à cidade não surge de caprichos intelectuais, mas sim das ruas, dos bairros, como o grito de oprimidos (Harvey, 2014, p. 15). 
O discurso decolonial busca tirar o véu de fenômenos como a gentrificação, observando-os para além de uma perspectiva eurocêntrica/progressista/capitalista, observada também no fenômeno expressões de racismos vários, como o ódio ao pobre. Nesse sentido, a decolonialidade dá uma resposta ao processo de colonialidade do poder, no presente caso por meio do direito à cidade.

Na medida em que a informalidade nas cidades latino-americanas gera uma gentrificação de caráter mais violento e evasivo, paralelo a isso gera também específicos centros de apoio e organização de espaços políticos como os "contra-poderes", o que hoje representa um obstáculo para a implementação rápida, fácil e suave de políticas gentrificadoras (Janoschka, 2016, p. 64-65). As falhas do sistema atual são evidentes: cidades divididas, fragmentadas e propensas a conflitos. As cidades cada vez mais transformam-se em cidades muradas, espaços públicos vigiados e excludentes (Harvey, 2014, p. 47).

0 direito à cidade é um direito coletivo, que significa o direito de comandar o processo urbano. A cidade é o local onde as diferenças vivem, de modo que diferentes pessoas com diferentes processos devem lutar umas com as outras para definir as formas da cidade. 0 problema com as cidades atuais, porém, é que na medida em que uma classe dominante controla os aspectos da cidade, não há interesse em fazer da cidade um local de coabitação de diferenças (Mitchell, 2003, p. 18).

0 direito à cidade, a reinvenção da cidade, é um dos direitos humanos mais importantes, e mais menosprezados. Reivindicar o direito à cidade é também reivindicar um poder configurador sobre os processos de urbanização, compreendendo a urbanização como um fenômeno de classe, pois os excedentes são extraídos de algum lugar ou de alguém, e o controle sobre o uso do lucro é retido na mão de poucos (Harvey, 2014, p. 30). 0 direito à cidade não é um simples direito de visita ou de retorno às cidades tradicionais, mas um direito à vida urbana, transformada, renovada. 0 direito à cidade é uma forma superior de outros direitos unidos, implicando assim: liberdade, individualização na sociedade, ao habitat e ao habitar, à obra, à apropriação (diferente do direito à propriedade) (Lefebvre, 2011, p. 134).

Vai muito além da liberdade individual de ter acesso a recursos urbanos, é um direito utilizado como defesa e também com potencial transformador da realidade das cidades. É uma arma nas mãos da população para contornar barreiras criadas e voltadas à exclusão social e para aquecimento do mercado, por exemplo, dando instrumentos de créditos para habitação. Para Opillard (2018, p. 139), as áreas urbanas desempenham aspectos particularmente marcantes de movimentos sociais contemporâneos, em geral o da luta contra as formas de vida criadas pelo mercado neoliberal, o que gera a mercantilização de aspectos da vida social, bem como formas de controle social.

Holm (2010, p. 91) defende que o direito à cidade, além de ressignificar o uso dos espaços da cidade, implica também o acesso aos debates políticos, o acesso dos habitantes às infraestruturas sociais ou cognitivas, tomando a cidade como um lugar de encontro, reconhecimento mútuo e deliberação. Nesse sentido, Campillo (2008, p. 167-171) aponta que a filosofia política ocidental sempre defendeu a liberdade e igualdade entre todos, porém, paralelo a isso, justificou a dominação e a desigualdade entre alguns seres humanos e outros. Essa situação não seria uma relação instituída politicamente, mas algo "natural". O direito à cidade, nesse contexto, deve ser objeto de luta, e não pode ser visto como um movimento linear para alcançá-lo, como etapa de uma evolução social (temos de interpretar segundo uma proposta genealógica).

Lefebvre (2011, p. 54-55), primeiro idealizador do conceito de direito à cidade, defendia que o espaço é uma construção social, pela estruturação e reestruturação urbana. 0 urbanismo seria uma ação de opressão frente ao usuário da cidade, pois esquece-se das necessidades sociais quando busca controlar o espaço para melhorar a vida cotidiana e criar novas relações sociais entre os habitantes. Nesse sentido, a cidade torna-se uma mediação das poderosas instituições públicas e privadas e da sociedade, através de estratégias urbanas que geram exclusão e segregação: políticas governamentais que privilegiam poucos, setores vinculados ao capital imobiliário. No seu pensar, de um lado haveria o urbano, e de outro a cidade. 0 espaço urbano é fragmentado e articulado, articulação reflexa da expressão espacial de processos sociais, ou seja, reflexo da sociedade. Por essa razão, em um contexto capitalista, as cidades são divididas em áreas segregadas, reflexo do presente e do passado. Na mesma medida que é desigual em razão da 
atual dinâmica, o espaço urbano também pode ser alterado, pois é mutável correspondendo ao ritmo social (Corrêa, 1989, p. 11-15).

As manifestações do direito à cidade constituem novos movimentos urbanos de contestações, pelas mais diversas formas: em Nova Orleans, pede-se acessibilidade no valor dos imóveis; em Madri, inquilinas prostitutas protestam pelo fato de serem marginalizadas em seu bairro; em Istambul, opunham-se a demolição de prédios; em Hamburgo, coletivos de artistas ocupam edifícios históricos para impedir projetos imobiliários. Os grupos, paralelamente, invocam a cidade em uma visão coletiva e também por uma visão autônoma dos grupos: reivindicam melhor qualidade dos serviços municipais, ou de melhores equipamentos de infraestrutura e, de outro lado, as mobilizações contra a expulsão de certos grupos sociais de seus bairros habituais ou a favor da manutenção de espaços autônomos provocam uma produtividade comum no contexto da economia cognitiva (Holm, 2010, p. 86).

Exemplos como os coletes amarelos na França, cujas reivindicações também giram em torno da caída de preços relacionados à habitação, pois, causadores de gentrificação, são revoltas mobilizadas pela classe média e baixa, insurgindo-se frontalmente; o congelamento dos preços dos aluguéis por cinco anos em Berlim, em decisão emanada em junho de 2019, tratou-se de pedidos realizados pela população como forma de colocar freio à especulação do mercado, reflexo de uma Alemanha na qual faltam habitações e paralelo ocorre um aumento exagerado nos preços, causando gentrificação (Müller, 2019); um manifesto em um grafite em junho de 2019, com o seguinte texto "Seu grafite sobe meu aluguel" ganha repercussão, pois a arte também pode ser forma de ocasionar gentrificação, pois aumenta a especulação próximo de onde é produzida. $\mathrm{O}$ alvo atacado foi a própria rua, e não um prédio comercial, o que destaca (Gómez Urzaiz, 2019); recentemente, a população se mobiliza em Berlim para retirar um mercado aburguesado que substitui um mercado que tinha grandes descontos, pois este novo estabelecimento causa gentrificação (Woolsey, 2019).

Assim, a gentrificação continua, hoje, a ser um conceito nocivo, associado à perpetuação de injustiças contra os pobres, reflexo de uma matriz de colonialidade do poder; e não positivo, como muitos defendem, destacando a destruição de casas e bairros para promover interesses de ricos e poderosos, acarretando, conforme posto, a exacerbação da injustiça urbana pelo desejo especulativo de exploração/especulação e criar um espaço exclusivo que impede os pobres e marginalizados de reivindicarem o direito à cidade (Shin, 2018, p. 153).

A gentrificação é, assim, um problema social criado, e sua resposta deve advir de políticas públicas (Marcuse, 2015, p. 1.265) e também pela judicialização ${ }^{14}$ como possibilidade de obstruir as políticas públicas gentrificadoras, ampliar os custos políticos para as decisões estatais e como potencial de negociação nos canais administrativos.

\section{Conclusões}

O pensamento crítico frente ao processo gentrificador deve desmontar os falsos lugares-comuns, desmascarar mentiras, extirpar o senso comum e apontar contradições do discurso predominante. 0 discurso hegemônico busca desmobilizar a potência do direito à cidade, o que deve ser denunciado, vendo-se a gentrificação como um problema social criado pelo homem, dando visibilidade a essa sua dimensão, juntamente a questões como violências simbólicas, reflexo da colonialidade do poder intrínseca à prática e à defesa do processo de gentrificação.

Conforme demonstrado, a globalização e sua conexão com a cidade, a revitalização de centros, a reurbanização, a turistificação, ou seja, o próprio avanço da urbanização em nada se relaciona com redução de desigualdades. Mais do que embelezamento urbano, a gentrificação esconde uma série de interesses; mais do que econômica, a gentrificação é parte e parcela de um projeto político e ideológico

\footnotetext{
${ }^{14}$ No ponto, o tema Medidas Estruturantes é muito interessante no que toca à judicialização de temas que envolvem o direito à cidade. Ver: Benente \& Thea (2017); assim como o estudo de Lima (2018).
} 
do Estado e das elites, que facilita a limpeza social, levando os menos desejáveis para longe do espaço urbano. Nesse sentido, a colonialidade integra o contexto da globalização e do pensamento linear global.

A importância de considerar as particularidades latinas e brasileiras é porque desarticulando as formas pelas quais a gentrificação se manifesta, torna-se possível a articulação de uma luta fundada no direito à cidade, uma vez que a gentrificação vem sempre acompanhada de um discurso higienizador e, muitas vezes, nem a própria população que é gentrificada consegue ver o discurso colonialista por detrás.

Em que pese a perspectiva crítica necessária para compreender a gentrificação ${ }^{15}$, teorias neoclássicas continuam a dominar as políticas urbanas devido ao triunfo do neoliberalismo, pois os governos atuam menos regulando os mercados para proteger os residentes marginalizados, o que faz parte do próprio planejamento estratégico do neoliberalismo. Nesse sentido, mais do que nunca o direito à cidade torna-se um direito fortalecido e importante para a sociedade.

0 processo e o conceito de gentrificação sempre estiveram envolvidos com a linguagem colonial inovação, criatividade, progresso - voltada a impulsos imobiliários e políticos - revitalização, regeneração, sustentabilidade. Insurgindo-se contra essas práticas coloniais, a decolonialidade é a energia escondida por baixo da retórica da modernidade, resposta dos humilhados, esquecidos, marginados, uma energia que não se deixa manejar pela lógica da colonialidade e não acredita nos contos de fada de sua retórica, local onde se localiza o direito à cidade. Nesse contexto global, as histórias locais são excluídas pelas globais, aumentando a potência da colonialidade do poder.

0 combate à gentrificação se inicia com propostas teóricas que desvelem a colonialidade do poder intrínseca à gentrificação, o que seria capaz de ampliar um possível processo de transformação do conceito. Com esse primeiro passo, ou seja, com o desvelamento do conceito de gentrificação, é possível criar uma massa maior de mobilização e também há maior força de movimentar e postular diante dos canais políticos e judiciais.

Essa proposta tem como adversário o pensamento hegemônico da colonialidade do poder, o qual hoje não somente domina o capital econômico, mas os demais capitais, como o cultural e o da produção de conhecimento, que deve ser desmantelada, permitindo assim tornar visíveis injustiças sociais como a gentrificação.

\section{Referências}

Amendola, G. (2000). La ciudad postmoderna. Madrid: Celeste Ediciones.

Atkinson, R. (2004). The evidence on the impact of gentrification: new lessons for the urban renaissance? International Journal of Housing Policy, 4(1), 107-131. http://dx.doi.org/10.1080/1461671042000215479.

Atkinson, R., \& Bridge, G. (2005). Globalisation and the new urban colonialism. In R. Atkinson, \& G. Bridge (Eds.), Gentrification in a global context: the new urban colonialism. New York: Routledge.

Bauman, Z. (2003). Comunidade: a busca por segurança no mundo global. Rio de Janeiro: Zahar.

Bauman, Z. (2009). Confiança e medo na cidade. Rio de Janeiro: Zahar.

Bello, E., \& Queiroz, M. (2017). 0 direito à cidade como prática de resistência a políticas de gentrificação e de remoções forçadas: o caso da comunidade metrô-mangueira (Rio de Janeiro). Revista de Direito da Cidade, 10(3), 1911-1940.

Benente, M., \& Thea, F. (Eds.). (2017). Derecho a la vivienda y litigio estructural. Buenos Aires: Edunpaz.

Betancur, J. (2014). Gentrification in Latin Americia: overview and critical analysis. Urban Studies Research, 2014, 1-14. http://dx.doi.org/10.1155/2014/986961.

\footnotetext{
${ }^{15}$ Conforme afirma Torres-Tovas (2019, p.8-9), o estudo da gentrificação desde uma perspectiva crítica permite que o fenômeno ganhe visibilidade, sendo também uma forma de abordar os conflitos que ocorrem nas cidades contemporâneas, que , para o autor, são campos de disputas de força desigual, que geram dinâmicas como o deslocamento, desapropriação e despejos, retratos de um desenvolvimento urbano desigual.
} 
Campillo, A. (2008). El concepto de lo político en la sociedad global. Barcelona: Herder.

Castro-Gómez, S., \& Grosfoguel, R. (2007). Giro decolonial, teoría crítica y pensamiento hierarquico. In S. Castro-Gómez, \& R. Grosfoguel (Eds.), El giro decolonial: reflexiones para una diversidad epistémica más allá del capitalismo global. Bogotá: Siglo del Hombre Editores.

Cócola Gant, A., Durán, G., \& Janoschka, M. (2016). La ciudad del siglo XXI: políticas públicas urbanas, desplazamientos y contestaciones. Íconos, 56(56), 11-18. http://dx.doi.org/10.17141/iconos.56.2016.2351.

Constela, C. V. (2013). Gentrificación y renovación urbana: abordajes conceptuales y expresiones en América Latina. Annales de Géographie, 33(1), 219-234.

Cordero, A. H. (2016). Gentrificación: orígenes y perspectivas. Revista del Departamento de Geografía, 4(6), 91-113.

Corrêa, R. L. (1989). O espaço urbano. São Paulo: Ática.

Davis, M. (2008). Planeta Favela. São Paulo: Boitempo.

Elliott-Cooper, A., Hubbard, P., \& Lees, L. (2020). Moving beyond Marcuse: gentrification, displacemente and the violence of un-homing. Progress in Human Geography, 44(3), 492-509. http://dx.doi.org/10.1177/0309132519830511.

Gómez Urzaiz, B. (2019, 8 de junho). “Seu grafite sobre o meu aluguel” o grito de guerra contra os 'descolados' que encarecem os bairros. Madrid: El País.

Graham, S. (2011). Cities under siege: the new military urbanism. New York: Verso.

Hall, S. (2006). A identidade cultural na pós-modernidade (11. ed.). Rio de Janeiro: DP\&A.

Harvey, D. (2014). Cidades rebeldes: do direito à cidade à revolução urbana. São Paulo: Martins Fontes.

Holm, A. (2010). Urbanisme néolibéral ou droit à la ville. Multitudes, 43(4), 86-91.

http://dx.doi.org/10.3917/mult.043.0086.

Janoschka, M. (2016). Gentrificación, desplazamiento, desposesión: procesos urbanos claves en América Latina. Revista INVI, 31(88), 27-71. http://dx.doi.org/10.4067/S0718-83582016000300002.

Janoschka, M., Sequera, J., \& Salinas, L. (2014). Gentrificación en España y América Latina: un diálogo crítico. Revista de Geografía Norte Grande, 58(58), 7-40. http://dx.doi.org/10.4067/S0718-34022014000200002.

Leão, F. P. S., Jr., \& Brito, C. S. (2018). 0 mercado habitacional e o processo de gentrificação em cidades latino-americanas: um estudo exploratório no bairro de Boa Viagem, Recife-PE. urbe. Revista Brasileira de Gestão Urbana, 10( Suppl 1), 68-81. http://dx.doi.org/10.1590/2175-3369.010.supl1.ao13.

Lees, L., Slater, T., \& Wily, E. (2008). Gentrification. New York: Routledge.

Lefebvre, H. (2011). O direito à cidade. São Paulo: Centauro.

Lima, F. D. S. (2018). Judicializando o direito à cidade no Brasil: estratégia para a mobilização jurídica e para participação cidadã? Revista de Direito da Cidade, 10(4), 2369-2391.

López-Morales, E., Shin, H. B., \& Lees, L. (2016). Latin American gentrifications. Urban Geography, 37(8), 1091-1108. http://dx.doi.org/10.1080/02723638.2016.1200335.

Maldonado-Torres, N. (2007). Sobre la colonialidad del ser: contribuciones al desarrollo de un concepto. In S. Castro-Gómez, \& R. Grosfoguel (Eds.), El giro decolonial: reflexiones para una diversidad epistémica más allá del capitalismo global. Bogotá: Siglo del Hombre Editores.

Maloutas, T. (2012). Contextual diversity in gentrification research. Critical Sociology, 38(1), 33-48.

http://dx.doi.org/10.1177/0896920510380950.

Marcuse, P. (2015). Gentrification, social justice and personal ethics. International Journal of Urban and Regional Research, 39(6), 1263-1269. http://dx.doi.org/10.1111/1468-2427.12319.

Mendes, L. F. G. (2015). As novas fronteiras da gentrificação na teoria urbana crítica. Revista Cidades, 12(20), 207-252. 
Mignolo, W. D. (2003). Históricas Locais/Projetos Globais: colonialidade, saberes subalternos e pensamento liminar. Belo Horizonte: Editora UFMG.

Mignolo, W. D. (2007). El pensamiento decolonial: desprendimiento y apertura: un manifiesto. In S. Castro-Gómez, \& R. Grosfoguel (Eds.), El giro decolonial: reflexiones para una diversidad epistémica más allá del capitalismo global. Bogotá: Siglo del Hombre Editores.

Mignolo, W. D. (2017). Colonialidade, o lado mais escuro da modernidade. Revista Brasileira de Ciências Sociais, 32(94), 1-17. http://dx.doi.org/10.17666/329402/2017.

Mitchell, D. (2003). The right to the city: social justice and the fight for public space. New York: The Guilford Press.

Müller, E. (2019, 19 de junho). Berlín congela el precio de los alquileres durante cinco años. Madrid: El País.

Neri, M. C. (2019). A escalada da desigualdade: qual foi o impacto da crise sobre a distribuição de renda e pobreza? Rio de Janeiro: FGV Social. Recuperado em 26 de agosto de 2019, de https://cps.fgv.br/desigualdade

Opillard, F. (2018). Comparer la dimension spatiale des luttes urbaines: analyse critique des mobilisations contre la gentrification à San Francisco (États-Unis) et contre la prédation immobilière à Valparaíso (Chili). Annales de Géographie, 720(2), 115-144. http://dx.doi.org/10.3917/ag.720.0115.

OXFAM Brasil. (2018). Relatório da desigualdade. Recuperado em 26 de junho de 2019, de https://www.oxfam.org.br/sites/default/files/arquivos/relatorio_desigualdade_2018_

Quijano, A. (2007). Colonialidad del poder y clasificación social. In: S. Castro-Gómez \& R. Grosfoguel (Eds.), El giro decolonial. Reflexiones para una diversidad epistémica más allá del capitalismo global. Bogotá: Siglo del hombre editores.

Quinteros, A. (2015). The colonized mind: place making and the right to the city. Technoetic Arts : a Journal of Speculative Research, 13(3), 323-329. http://dx.doi.org/10.1386/tear.13.3.323_1.

Rolnik, R. (1995). O que é a cidade. São Paulo: Brasiliense.

Rolnik, R. (2019). Guerra dos lugares: a colonização da terra e da moradia na era das finanças. São Paulo: Boitempo.

Shin, H. (2018). Studyng global gentrification. In J. Harrison, \& M. Hoyler (Eds.), Doing gloal urban research. London: Sage.

Smith, N. (2012). La nueva frontera urbana: ciudad revanchista y gentrificación. Madrid: Traficante de Sueños.

Sousa Santos, B. (2007). Para além do Pensamento Abissal: das linhas globais a uma ecologia de saberes. Revista Critica de Ciencias Sociais, 78(78), 3-46. http://dx.doi.org/10.4000/rccs.753.

Sousa Santos, B. (2010). Descolonizar el saber reiventar el poder. Montevideo: Trilce.

Torres-Tovar, A. (2019). Globalización, mercantilización, clústers y gentrificación en la ciudad. Bitacora, 29(1), 7-10. http://dx.doi.org/10.15446/bitacora.v29n1.76498.

Woolsey, B. (2019, 9 de maio). Berlin anti-gentrification activists fight to keep...the local Aldi. United Kingdom: The Guardian.

Wyly, E. (2019). The evonlving state of gentrification. Tijdschrift voor Economische en Sociale Geografie, 110(1), 12-25. http://dx.doi.org/10.1111/tesg.12333.

Zapata, M. C., Diaz, M. P., \& Díaz Parra, I. (2018). Clases sociales, renovación urbana y gentrificación: miradas desde América Latina. Quid 16: Revista del Área de Estudios Urbanos del Instituto de Investigaciones Gino Germani de la Facultad de Ciencias Sociales, (9), 1-8.

Editor: Rodrigo Firmino

Recebido: Set. 04, 2019

Aprovado: Maio 25, 2020 